\title{
Preparation and Characterization of PVA-Cellulose Micro Crystal Composite Film from Jute fiber
}

\section{Md. Zahid Hasan}

BGMEA University of Fashion and Technology

\section{Yeasin Arafat}

Mawlana Bhashani Science and Technology University

M. Mahbubul Bashar ( $\sim$ bashar.te@mbstu.ac.bd)

Mawlana Bhashani Science and Technology University https://orcid.org/0000-0001-8054-809X

\section{Md. Nabi Newaz Niloy}

University of Dhaka: Dhaka University

Md Imranul Islam

State University of New York at Stony Brook: Stony Brook University

\section{Shahjalal Khandaker}

Dhaka University of Engineering and Technology

\section{A. M Sarwaruddin Chowdhury}

University of Dhaka: Dhaka University

\section{Research Article}

Keywords: Composite film, cellulose microcrystals, natural fiber, PVA, oxidation method

Posted Date: August 27th, 2021

DOl: https://doi.org/10.21203/rs.3.rs-850096/v1

License: (c) (1) This work is licensed under a Creative Commons Attribution 4.0 International License.

Read Full License 


\section{Abstract}

Herein, the microcrystalline cellulose (MCC) was obtained from jut fiber by ammonium persulfate (APS) oxidation process and thus polyvinyl alcohol (PVA) composite films were prepared by the reinforcement of MCC in a solution casting method. The surface chemistry, thermal properties and surface morphology of MCC and PVA-MCC composite films were studied by FT-IR spectroscopy, thermogravimetric analyzer and scanning electron microscopy. The SEM images confirmed the rod like MCC with average particle diameter $4.6 \mu \mathrm{m}$ and length in $48.4 \mu \mathrm{m}$. The FT-IR spectroscopy revealed the complete removal of lignin and hemicellulose from jute fiber. A peak at $1730 \mathrm{~cm}^{-1}$ was introduced in MCC due to oxidation with APS. The absorption peak of $-\mathrm{OH}$ groups in PVA-MCC composite films were shifted, somewhat disappeared and weakened due to the intra and inter molecular hydrogen bonding of $\mathrm{MCC}$ and $\mathrm{OH}$ groups in PVA. Thermogravimetric analysis expressed the thermal behavior of MCC and PVA-MCC composite films. Initially the thermal stability of PVA-MCC composite films was lower than the pristine MCC but at higher temperature $\left(>300^{\circ} \mathrm{C}\right)$ it showed better stability indicating the applicability of the composite at higher temperature.

\section{Introduction}

With the growing concern of the adverse effect of countless non-biodegradable and non-renewable materials, a great deal of momentum to counteract this effect is prevailing from all levels of stake-holders of the society. As of 2020 , about three-fourth $(73.8 \%$ ) of the world textile fiber consumption is comprised of man-made fibers with a constant growing demand [1]. Since the synthetic fibers are non-biodegradable and coming from non-renewable resource, they lead an unsustainable cycle of production and consumption. In addition, the environment concern and long-term economic goal have raised an appreciable impetus to think about environment friendly composite materials. In this regard, cellulose based composite materials have attracted the ample attention towards the researchers of the world. Although there exist a number of different variety of biomass and organic materials for example grass, agricultural crops, and wood or wastes are significant renewable resources. Among them, cellulose is the most abundant and ubiquitous natural polymer in the eco-system [2-4]. The worldwide cellulose production is approximately $10^{12}$ tons per annum [5-7]. Due to some novel attributes such as renewability, biodegradability, nontoxicity, and improved mechanical properties, low thermal expansion, low density and light weight cellulose can be applied in the field of pharmaceutical, medical, biomedical, construction, automotive, cosmetic and packaging industries [8-11]. Traditionally, cellulose is extracted from the wood which contains only $45 \%$ cellulose $[2,5]$. The other non-woody fibers such as hemp, sisal, flax, though contain higher amount of cellulose, these fibers are less important in terms of economy and world production [12]. In this context, jute fiber is the attractive and competent alternative for cellulose as

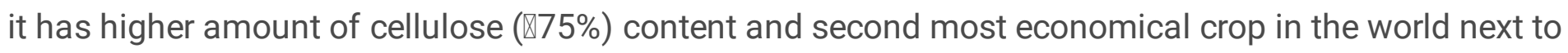
cotton $[12,13-15]$. Several attempts have been deployed to extract micro-nanocellulose from jute fiber. The prominent examples are acid hydrolysis [16], steam explosion [17, 18], TEMPO mediated oxidation [19] and oxidation with ammonium persulfate [12]. Among them APS oxidized cellulose contain 
carboxylic functional moieties due to the direct oxidation in the $\mathrm{C} 6$ position of the glucose ring of the cellulose chain $[20,21]$.

Polyvinyl alcohol (PVA) is water-soluble and colorless synthetic resin. Due to presence of hydroxyl groups, PVA shows excellent film-forming capability by creating intermolecular hydrogen bond $[22,23]$. The barrier, mechanical and thermal properties of PVA film can be improved by reinforcing filler materials like cellulose [24], titanium [25], collagen [26], carbon nanotubes [27], silica [28], chitosan [29], and so on. An overarching goal of this research is to develop a composite film of PVA reinforced with microcrystalline cellulose obtained from jute fiber by single step APS oxidation method. The carboxylated MCC from jute fiber cross-linked with PVA through ester linkage or intra and inter molecular $\mathrm{H}$-bonding resulted the improved thermal properties of the composite films at an elevated temperature. In this study the surface topography, surface chemistry and thermal properties of MCC and PVA-MCC composite films were investigated. The knowledge gathered from this study might lead the applicability of this PVA-MCC composite at different conditions.

\section{Materials And Methods}

\section{Materials}

Jute fiber was purchased from Sirajganj district of Bangladesh. Polyvinyl alcohol (PVA, molecular weight: 1, 25,000 degree of polymerization: $1700-1800$, Viscosity: 25-32 cps, hydrolysis (mole \%): 98-99, volatile matter: $\max 5 \%$, Ash: $\max 0.7 \%, \mathrm{pH}(0.2 \%$ in water): $5.0-7.0)$ was purchased from Research-Lab Chem Industries, India. Ammonium per sulfate (Extra Pure) was purchased from Daejung Chemicals \& Metals Co. Ltd., Korea.

\section{Extraction of microcrystalline cellulose from jute fiber and preparation of PVA-MCC film}

The jute fiber was washed with water and ethanol twice to remove the dust and dirt. The fiber was chopped into pieces and oxidized with $1.0 \mathrm{M}$ ammonium persulfate at $60^{\circ} \mathrm{C}$ for 3,6 and 12 hours. The obtained cellulose powder was washed with de-ionized water for several time and vacuum dried. The powder form microcrystalline cellulose was stored and used for film preparation and characterization.

The PVA-MCC film was prepared by film casting method published previously [30]. Briefly MCC powder and PVA was taken in different ratios such as 50:50, 60:40, 80: 20 and 90:10. The required amount of MCC and PVA was dispersed or dissolved in water. The two solution was mixed homogenously by stirring 8 hours at room temperature. The mixture of MCC and PVA solution was then poured in a Petri dish. The petri dish was coated with silicone film which facilitated the easy release of the PVA-MCC film from the surface.

\section{Characterization of MCC and PVA-MCC film}


The surface chemical structure of MCC and PVA-MCC film were characterized by FT-IR spectroscopy (Shimadzu, Japan) with a spectral resolution $4 \mathrm{~cm}^{-1}$. The content of carboxylic group was quantified through conductometric titration using a conductometer Multi 9310 IDS, Germany as described elsewhere. ${ }^{31}$ The surface topography was investigated with scanning electron microscopy (JEOL, JSM6490LA, Japan). Thermogravimetric analysis (TGA) was examined using TGA measurement instrument (Shimadzu, TGA-50H, Japan.) at a heating rate of $10^{\circ} \mathrm{C} / \mathrm{min}$ under $\mathrm{N}_{2}$ flow condition into the combustion chamber.

\section{Results And Discussion}

\section{MCC extraction and hybrid film formation}

Microcrystalline cellulose was extracted from jute fiber by simple APS oxidation method without pretreatment following the previous reports $[12,20]$. Briefly, the mechanically ground jute fiber was placed in a reaction vessel with $1.0 \mathrm{M}$ APS and heated at $60^{\circ} \mathrm{C}$ for 3,6 and 12 hours. The complete removal of non-cellulosic carbohydrates from jute fiber was achieved within 3 hour oxidation period. However, this oxidation time span was unable to disintegrate the cellulose from jute fiber. The further increase in oxidation time in 6 and 12 hours resulted the micro cellulose and complete powder from was obtained by 12 hours oxidation. The Fig. 1(a-c) shows the photographs of jute cellulose in different stages of oxidation.

Microcrystalline powder cellulose was used to produce hybrid film with poly (vinyl alcohol) (PVA). Different mixing ratio of MCC and PVA was exploited to produce the hybrid film. The Fig. 1 (d-f) represents the photographs of 50:50, 60:40 and 80:20 film of MCC and PVA respectively. The uniform film formation was obtained with the increase of the MCC content in the film. The lower proportions of MCC exhibited several cracks in the film and created difficulties in peeling of the film from the surface (fig ( $d$ and e)). The successful film was possible with 80:20 mixing ratio of MCC and PVA resulted the uniform and flawless film with easy removal from the surface.

\section{Surface morphology of MCC and PVA-MCC films}

The surface topography of MCC and PVA-MCC composite films were investigated with scanning electron microscope (SEM). The SEM images of MCC confirmed the rod like structure of MCC (Fig. 2(a)). The vigorous treatment of jute fiber with strong oxidizing agent APS resulted the removal of non-cellulosic substances such as lignin and hemicellulose. As the oxidation time further proceeds the jute cellulose was longitudinally decreased as well as reduced the dimeter of the fiber. As a result the aspect ratio (length: diameter) of the resultant fiber was increased. The distribution of diameter and length of the MCC is presented in Fig. 2 (b) and 2(c) respectively. The average diameter and length of the microcrystal was found 4.6 and $48.4 \mu \mathrm{m}$. The Fig. 2(d) shows the PVA-MCC composite film with the corresponding SEM images of the film presented in Fig. 2(e) and 2(f). The SEM image confirmed the random distribution of MCC in PVA matrix. In fact, the MCC was embedded in the surface of the film (Fig. 2(f)). The uneven 
distribution of crevices and cracks were also observed over the surface with miscellaneous sized and shaped of MCC.

Surface chemistry of MCC and PVA-MCC composite film

The surface chemistry of MCC and PVA-MCC composite films was investigated by FT-IR spectroscopy and conductometric titration method. The Fig. 3(a) depicts the typical FT-IR spectra of jute fiber and MCC oxidized with APS in different time span. The characteristic cellulosic peaks were clearly appeared in MCC indicating successful isolation of cellulose from jute fiber. The typical O-H peaks of cellulose was visible at nearly $3400 \mathrm{~cm} \otimes^{1}$ and antisymmetric and symmetric stretching vibrations of $-\mathrm{CH}_{2}$ in alkyl chain was observed at 2904 and $2890 \mathrm{~cm}^{-1}$ respectively [32]. A new peak appeared in $1730 \mathrm{~cm}^{-1}$ for $\mathrm{C}=0$ stretching vibrations of carboxylic group in MCC. The incorporation of this particular peak was due to the oxidation of $\mathrm{C} 6$ carbon of glucosyl residue of cellulose [12]. In contrast, pristine jute fiber also exhibited carboxylic peak at $1725 \mathrm{~cm}^{-1}$ region which was due to the uronic ester or acetyl groups of hemicellulose [9]. But as the oxidation proceeds the intensity of this peak decreased substantially indicating the removal of hemicellulose from the jute fiber surface during the early stage of oxidation. This indication is shown by the MCC after $3 \mathrm{~h}$ of oxidation presented in red line. As the oxidation further proceeded the $\mathrm{C}=0$ stretching vibration newly appeared in the $\mathrm{C} 6$ carbon of cellulose chain. On the contrary, the MCC of different oxidation time was free from lignin as their FT-IR spectra did not exhibit any peak at 1254 and $1502 \mathrm{~cm}^{-1}$ responsible for lignin which is vividly present in jute fiber [33]. The other ordinary peaks of cellulose at $1606 \mathrm{~cm} \nabla^{1}$ represents the absorbed water [34, 35], $1429 \mathrm{~cm} \nabla^{1}$ expressed the $\mathrm{CH}_{2}$ bending [36] and the peak at $1060 \mathrm{~cm} \nabla^{1}$ and $898 \mathrm{~cm} \nabla^{1}$ were associated with saccharine structure ${ }^{37}$ was common and found both in jute fiber and MCC. But in case of MCC these cellulosic peaks are more exposed than the jute fiber which is very relevant as the raw jute fiber is cemented with several types of noncellulosic polysaccharides such as hemicellulose and lignins, wax etc. Consequently, the MCC obtained from jute fiber was completely free from lignin and hemicellulose and the relative amount of cellulose was higher in MCC than the jute fiber. The generation of carboxylic moieties at C6 position of cellulose chain was further quantified by conductometric titration. The Fig. 3(b) shows the typical conductometric titration of MCC obtained from jute fiber. It clearly indicates three regions for strong acid, weak acid and excess amount of alkali addition. As the mobility of $\mathrm{H}^{+}$ion is faster the conductivity decreased sharply up to the valley between volume $V_{1}$ and $V_{2}$. In this region the change of conductivity is almost constant. The added $\mathrm{OH}^{-}$was consumed for the neutralization of weak carboxylic acid in cellulose chain generated through the oxidation with APS. The amount of carboxylic group charge density was found 320, 180 and 760 $\mathrm{mmol} / \mathrm{kg}$ for raw jute fiber and MCC for $3 \mathrm{~h}$ and $12 \mathrm{~h}$ oxidation time respectively. This investigation is well in agreement with the FT-IR spectroscopic studies of the jute fiber and MCC.

The surface chemistry of PVA-MCC composite films was also studied with FT-IR spectroscopy. The Fig. 3(c) denotes the FT-IR spectra of 40/60 and 20/80 PVA-MCC composite films. In PVA-MCC composite film the stretching vibration of hydroxyl groups shifted to lower wavenumber at $3330 \mathrm{~cm} \rrbracket^{1}$ implying the intermolecular or intramolecular hydrogen bonding with MCC and PVA or within PVA itself respectively. A 
peak at $1720 \mathrm{~cm}^{-1}$ was observed in both the films confirming the stretching vibration of carbonyl functional group originated either from the ester linkage between - $\mathrm{COOH}$ groups of $\mathrm{MCC}$ and $-\mathrm{OH}$ group of PVA or residual acetate group remained in PVA due to the hydrolysis of polyvinyl acetate to polyvinyl alcohol during preparation and processing [38]. Another peak at $1265 \mathrm{~cm}^{-1}$ was found in the composite films ascertaining the ester linkage with MCC and PVA. However, we predict the intra and intermolecular $\mathrm{H}$-bonding with MCC and PVA in the composite films. The other cellulosic peaks at $1100-1055 \mathrm{~cm} \nabla^{1}$ responsible for $\mathrm{C}-\mathrm{O}-\mathrm{C}$ and $1153 \mathrm{~cm} \rrbracket^{1}$ for $\mathrm{C}-0$ shifted to lower energy state than the $\mathrm{MCC}$ and became weaker in intensity. The more prominently, absorption peak of $-\mathrm{OH}$ groups were shifted, somewhat disappeared and weakened due to the interaction of MCC and OH groups in PVA [39]. These findings supported the formation of new intra or inter-molecular hydrogen bonds as well as conformation change within MCC and PVA [40].

Thermal properties analysis

The thermal stability of MCC and PVA-MCC composite films was investigated by thermogravimetric (TGA) analysis. It is well established that the degradation of cellulose encompasses depolymerization and dehydration along with decomposition of glycosyl units of cellulose chain in parallel [41, 42]. The initial decomposition at around $100^{\circ} \mathrm{C}$ was mostly accompanied by the evaporation of moisture and low molecular weight compounds and oligomers in all the samples. The decomposition of jute fiber started at $275^{\circ} \mathrm{C}$ whereas MCC and PVA-MCC decomposed much early at $250^{\circ} \mathrm{C}$ and $190^{\circ} \mathrm{C}$ respectively. On the contrary, the maximum decomposition temperature of MCC and PVA-MCC films were found $334^{\circ} \mathrm{C}$ and $325^{\circ} \mathrm{C}$ were also less than that of jute fiber $\left(340^{\circ} \mathrm{C}\right)$. Consequently, it is obvious that APS oxidized MCC exhibited low thermal stability which is conformed the other reports of cellulose $[43,44]$.

This phenomenon might be attributed owing to the comparative small particle size, high specific surface area thereby low resistance towards heat and presence of active surface groups than the raw jute cellulose [45]. On the other hand thermal stability of PVA-MCC composite films of different composition was lower than the MCC and jute fiber at the temperature ranges $140^{\circ} \mathrm{C}$ to $340^{\circ} \mathrm{C}$. However, the composite films exhibited better thermal stability beyond the temperature at $350^{\circ} \mathrm{C}$. The residual mass of MCC, PVA-MCC film with $40 / 60$ and $20 / 80$ composition at $400^{\circ} \mathrm{C}$ was $23.5,29.7$ and $31 \%$ respectively. This improved thermal stability of the composite films might be due to the interaction of MCC and PVA through $\mathrm{H}$-bonding or covalent bonding with the ester linkage with MCC and hydroxyl groups of PVA. The resistance of PVA-MCC composite films widen the scope of processing at higher temperature.

\section{Conclusions}

This study validates the composite film formation of carboxylated MCC from jute fiber with water soluble PVA polymer. The maximum $80 \% \mathrm{MCC}$ was incorporated into the hybrid film. The surface morphology of the composite film confirmed the rough surface and opaque film where MCC was found embedded in the PVA matrix. The surface chemistry of the MCC showed carboxylic group containing MCC without any non-carbohydrate polysaccharides. The strong ester linkage formation was plausible as well as various 
$\mathrm{H}$-bonding interaction was confirmed in the composite films and thus indicated improved thermal stability of the film at the higher temperatures. The stability of the composite film at elevated temperatures widens the scope of using MCC at broader spectrum of applications. As jute is widely cultivated in Bangladesh, it has profound socioeconomic impact for the jute farmers as well as the country's economy. This study might open new areas of integrating jute in many different combinations of composite materials. Further study (e.g., biodegradation, crystal structure and mechanical properties such as tensile and bursting strength) on this PVA-MCC film can be carried out to explore more end uses of it. Since, this is a cellulose- 1 based opaque film, further study is recommended to impart transparency and conductivity to the film which can be used as flexible electronics. A limitation in this study was unable to develop larger film as film casting method is only able to create a smaller sized film. In addition, the developed PVA-MCC film is water soluble in nature which facilitates an opportunity to adhere hydrophobicity by further research.

\section{References}

1. The International Cotton Advisory Committee [ICAC], (2020)

2. Zhu H, Luo W, Ciesielski PN, Fang Z, Zhu JY, Henriksson G, Himmel ME, Hu L (2016) Chem Rev 116:9305

3. Jung YH, Chang TH, Zhang H, Yao C, Zheng Q, Yang VW, Mi H, Kim M, Cho SJ, Park DW, Jiang H (2015) Nat Commun 6:1

4. Zhu H, Fang Z, Preston C, Li Y, Hu L (2014) Energy Environ Sci 7:269

5. Moon RJ, Martini A, Nairn J, Simonsen J, Youngblood J (2011) Chem Soc Rev 40:3941

6. Zimmermann T, Bordeanu N, Strub E (2010) Carbohydr Polym 79:1086

7. Jamshaid A, Hamid A, Muhammad N, Naseer A, Ghauri M, Iqbal J, Rafiq S, Shah. NS (2017) CHEMBIOENG REV 4:240

8. Rahman MM, Afrin S (2014) P. Haque Prog Biomater 3:23

9. Mathew AP, Oksman K, Sain M (2005) J Appl Polym Sci 97:2014

10. Kotek R (2008) Polym Rev 48:221

11. Hoenich NA (2006) BioResources 1:270

12. Bashar MM, Zhu H, Yamamoto S, Mitsuishi M (2019) Cellulose 26:3671

13. Mwaikambo LY, Ansell MP (2002) J Appl Polym Sci 84:2222

14. Thomas MG, Abraham E, Jyotishkumar P, Maria HJ, Pothen LA, Thomas S (2015) Int J Biol Macromol 81:768

15. Bashar MM, Siddiquee MA (2015) M. A. Khan Carbohydr Polym 120:92

16. Abraham E, Deepa B, Pothan LA, Jacob M, Thomas S, Cvelbar U, Anandjiwala R (2011) Carbohydr Polym 86:1468

17. Jahan MS, Saeed A, He Z, Ni Y (2011) Cellulose 18:451 
18. Wang H, Huang L, Lu Y (2009) FIBER POLYM 10:442

19. Cao X, Ding B, Yu J, Al-Deyab SS (2012) Carbohydr Polym 90:1075

20. Leung AC, Hrapovic S, Lam E, Liu Y, Male KB, Mahmoud KA, Luong JH (2011) Small 7:302

21. Leung AC, Lam E, Chong J, Hrapovic S, Luong JH (2013) J Nanopart Res 15:1

22. Mustafa P, Niazi MB, Jahan Z, Samin G, Hussain A, Ahmed T, Naqvi SR (2020) J Food Saf 40:12725

23. Li W, Yue J, Liu S (2012) Ultrason Sonochem 19:479

24. Li W, Wu Q, Zhao X, Huang Z, Cao J, Li J, Liu S (2014) Carbohydr Polym 113:403

25. Rajesh K, Crasta V, Kumar NR, Shetty G (2019) P. D. Rekha J Polym Res 26:1

26. Sionkowska A, Skopinska-Wisniewska J, Wisniewski M (2009) J Mol Liq 145:135

27. Paiva MC, Zhou B, Fernando KA, Lin Y, Kennedy JM, Sun YP (2004) Carbon 42:2849

28. Yu Z, Li B, Chu J, Zhang P (2018) Carbohydr Polym 184:214

29. Huang D, Wang A (2013) RSC Adv 3:1210

30. Baheti V (2013) JMilitky FIBER POLYM 14:133

31. Zhang Y, Karimkhani V, Makowski BT, Samaranayake G (2017) S. J Rowan Macromolecules 50:6032

32. Sain M, Panthapulakkal S (2006) Ind Crops Prod 23:1

33. Nakagaito AN, Yano H (2008) Cellulose 15:323

34. Carrillo I, Mendonça RT, Ago M, Rojas OJ (2018) Cellulose 25:1011

35. Ahmadpoor P, Nateri AS, Motaghitalab V (2013) J Appl Polym Sci 130:78

36. Kargarzadeh H, Ahmad I, Abdullah I, Dufresne A, Zainudin SY, Sheltami RM (2012) Cellulose 19:855

37. Kumar HN, Prabhakar MN, Prasad CV, Rao KM, Reddy TA, Rao KC, Subha MC (2010) Carbohydr

Polym 82:251

38. Korbag I, Mohamed Saleh S (2016) Int J Environ Stud 73:226

39. Han X, Chen S, Hu X (2009) Desalination 240:21

40. Oh SY, Yoo DI, Shin Y, Kim HC, Kim HY, Chung YS, Park WH, Youk JH (2005) Carbohydr Res 340:2376

41. Lin YC, Cho J, Tompsett GA, Westmoreland PR, Huber GW (2009) J Phys Chem 113:20097

42. Yang $H$, Yan $R$, Chen $H$, Lee DH, Zheng $C$ (2007) Fuel 86:1781

43. Sehaqui H, Kulasinski K, Pfenninger N, Zimmermann T, Tingaut P (2017) Biomacromol 18:242

44. Cheng M, Qin Z, Liu Y, Qin Y, Li T, Chen L, Zhu M (2014) J Mater Chem A 2:251

45. Habibi Y, Lucia LA, Rojas OJ (2010) Chem Rev 110:3479

\section{Table 1}

Table: 1 Thermal properties of jute, MCC and PVA-MCC composite films of different composition 


\begin{tabular}{|lllllllll|}
\hline Sample & $\mathrm{T}_{5 \%}$ & $\mathrm{~T}_{\text {Onset }}$ & $\mathrm{T}_{\max }$ & \multicolumn{5}{l|}{ Mass (\%) at temperature } \\
\cline { 8 - 10 } & ${ }^{\circ} \mathrm{C}$ & ${ }^{\circ} \mathrm{C}$ & ${ }^{\circ} \mathrm{C}$ & $300^{\circ} \mathrm{C}$ & $350^{\circ} \mathrm{C}$ & $400^{\circ} \mathrm{C}$ & $450^{\circ} \mathrm{C}$ & $500^{\circ} \mathrm{C}$ \\
\hline Jute & 100 & 275 & 340 & 80 & 38 & 22 & 13 & 3 \\
\hline MCC & 95 & 250 & 334 & 68 & 42 & 23 & 12 & 3.5 \\
\hline $60 \%$ MCC+ 40\% PVA film & 150 & 170 & 322 & 58 & 40 & 29 & 22 & 15 \\
\hline $80 \%$ MCC+ 20\% PVA film & 140 & 190 & 325 & 60 & 43 & 31 & 23 & 16 \\
\hline
\end{tabular}

\section{Figures}

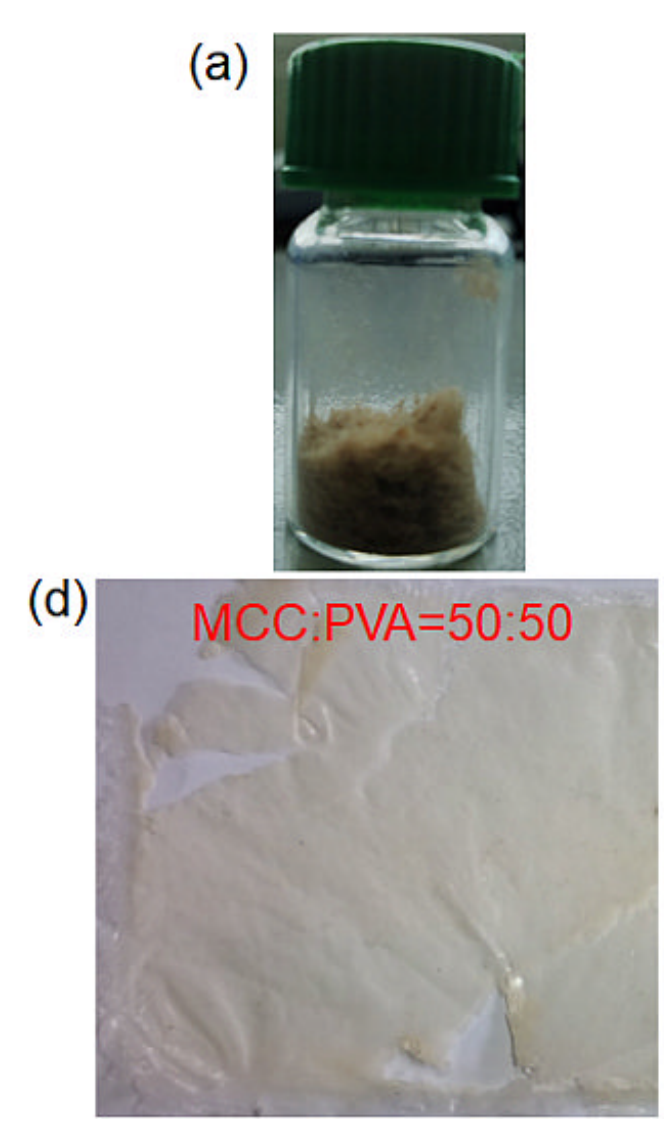

(b)

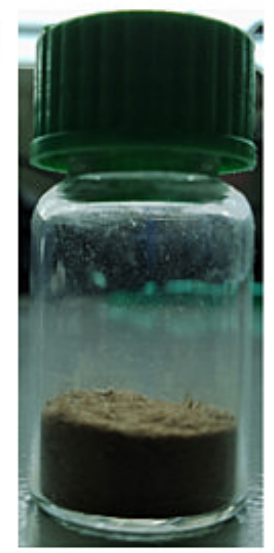

(e)

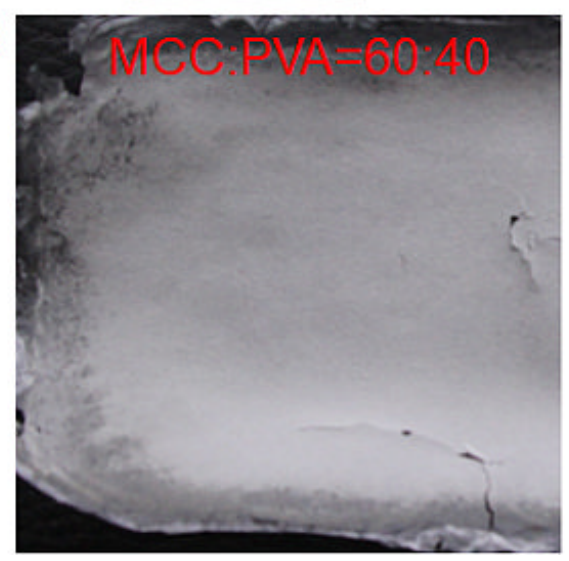

(c)

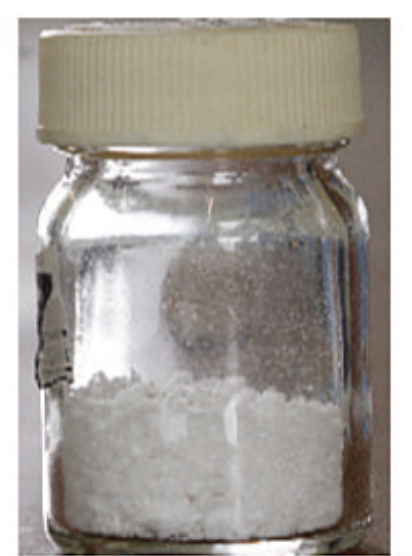

(f)

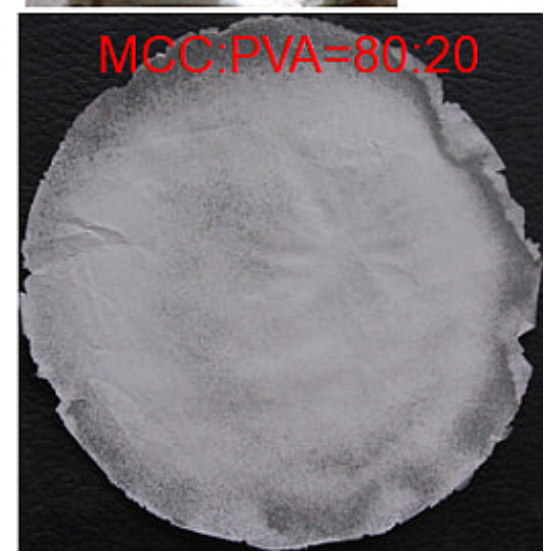

Figure 1

Photographs of cellulose extracted from jute fiber by APS oxidation (a) $3 \mathrm{~h} \mathrm{(b)} 6 \mathrm{~h}$, (d) $12 \mathrm{~h}$ and film formation with MCC at $12 \mathrm{~h}$ oxidation in different mixing ratio with PVA (d) 50:50, (e) 60:40 and (f) 80:20. 


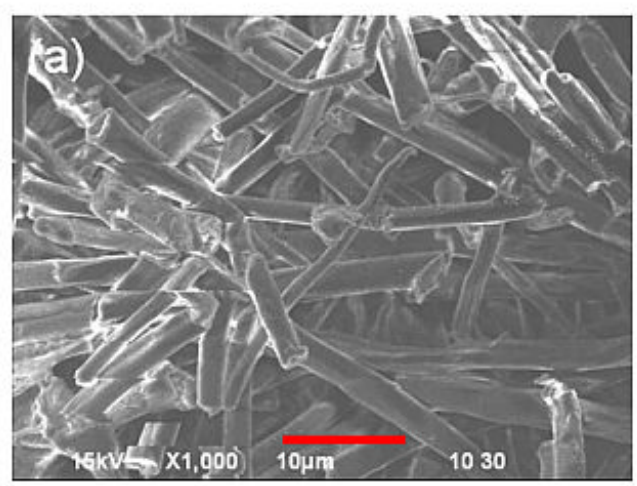

(b)

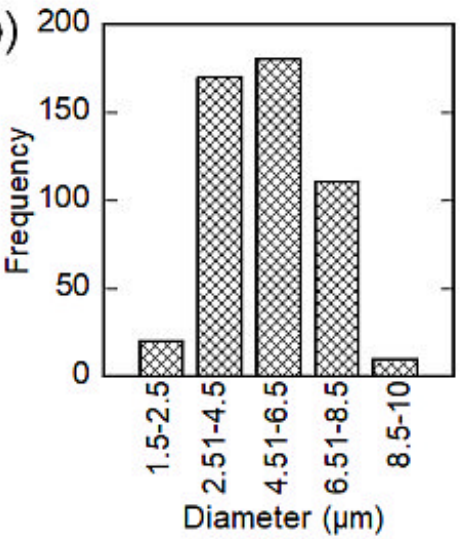

(c)

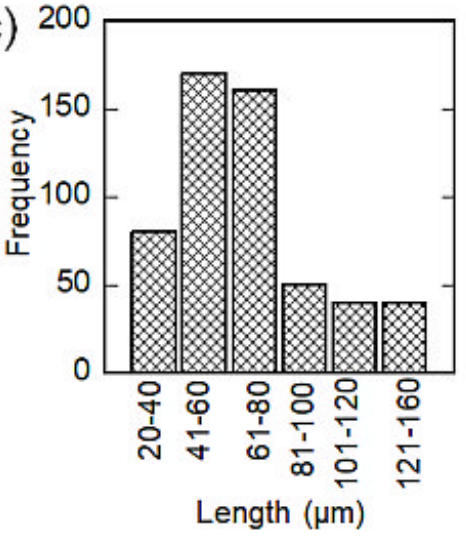

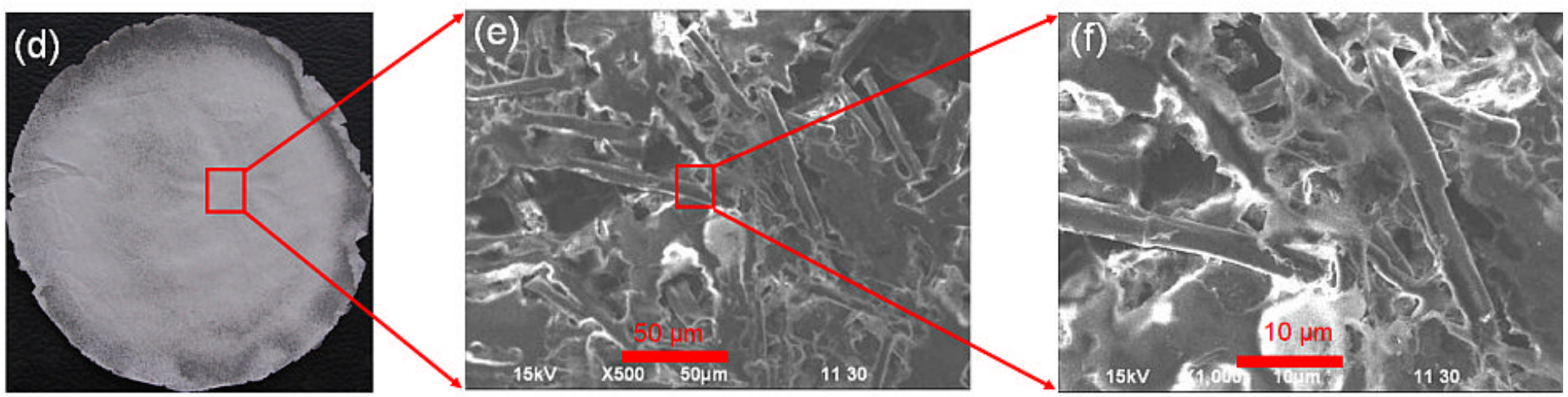

Figure 2

Surface morphology of MCC and PVA-MCCA composite films. SEM image of (a) MCC isolated from jute fiber, (b) and (c) diameter and length distribution of MCC respectively. Photograph of (d) 20/80 PVA-MCC composite film, (e) SEM image of composite film and (f) magnification of the area indicating the MCC embedded in the PVA matrix. 
(a)

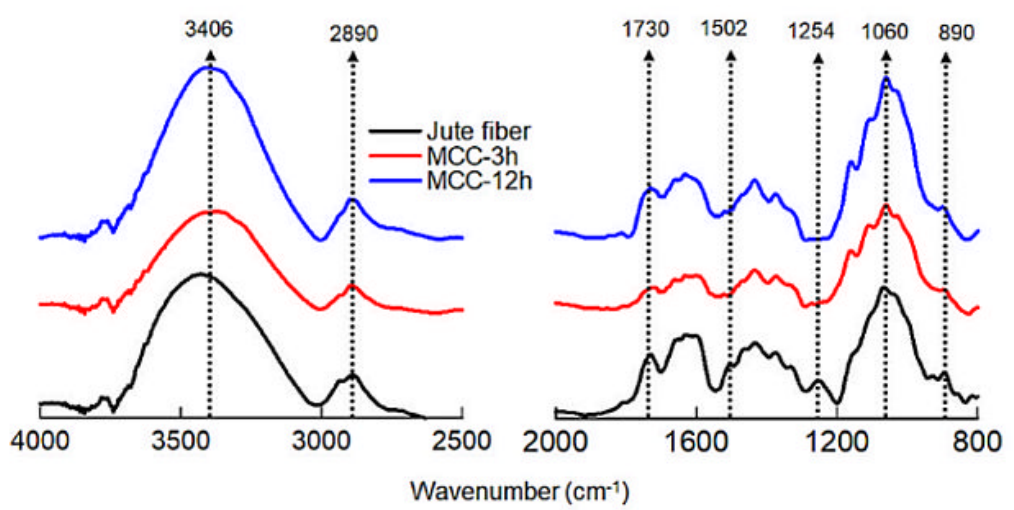

(b)

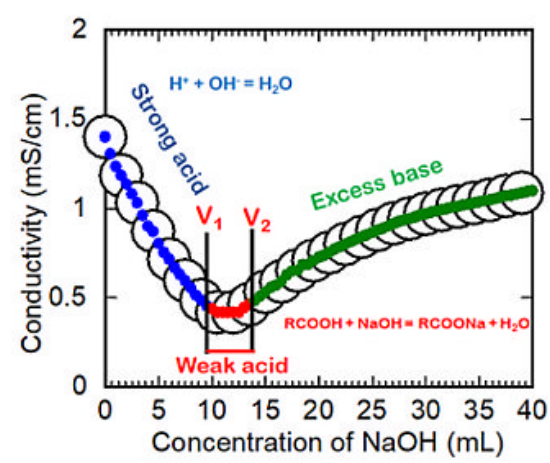

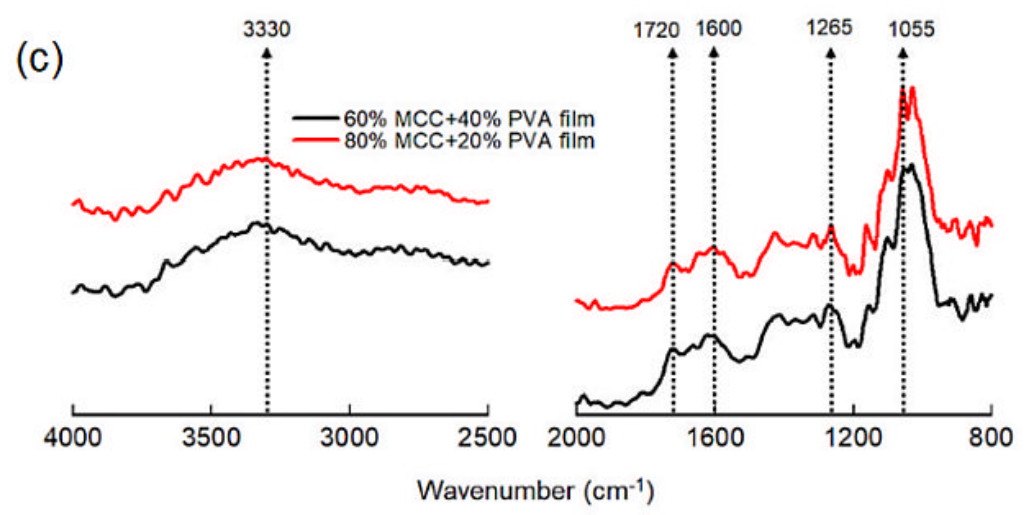

Figure 3

Surface chemical structure of jute fiber, MCC and PVA-MCC composite films. FT-IR spectra of (a) jute fiber and MCC of different oxidation time, (b) typical conductometric titration curve of MCC obtained from jute fiber by APS oxidation in $12 \mathrm{~h}$ time and (c) FT-IR spectra of PVA-MCC composite films of different composition. 


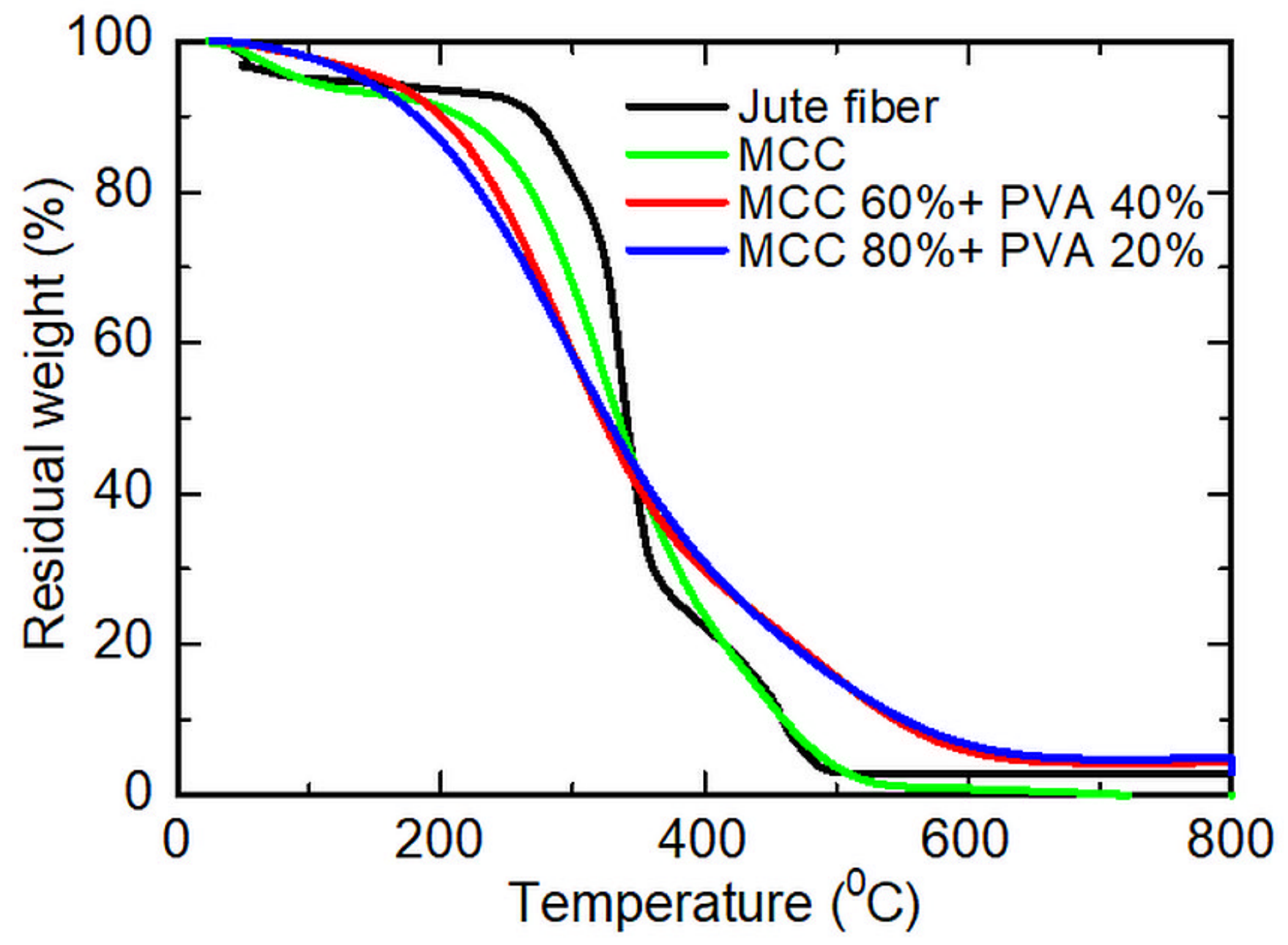

Figure 4

Thermogravimetric analysis (TGA) curves of jute fiber, MCC and PVA-MCC composite films of different composition. 